\title{
DOS IMPACTOS DO DISCURSO DE ÓDIO HOMOFÓBICO NO AMBIENTE
} INFORMÁTICO

\author{
Caio Eduardo Costa Cazelatto ${ }^{1}$ \\ Valéria Silva Galdino Cardin ${ }^{2}$
}

\section{RESUMO}

A presente pesquisa analisou, por meio do método teórico, os impactos que o discurso de ódio homofóbico acarreta ao ambiente informático. Para isso, explorou-se a Sociedade da Informação enquanto um novo paradigma social. Do mesmo modo, investigou-se o âmbito digital como uma nova categoria do meio ambiente. Posteriormente, apresentou-se as delimitações do discurso do ódio homofóbico, posicionando-o como um ato discursivo que transgride o direito à liberdade de expressão e afeta drasticamente a vivência dos indivíduos hetero-cis-discordantes. Por fim, demonstrou-se que esse discurso ao ser propagado no meio digital degrada o seu equilíbrio, revestindo-se como um elemento poluidor desse espaço.

Palavras-chave: Discurso de ódio; Homofobia; Meio ambiente informático.

\section{IMPACTS OF DISCOURSE OF HOMOPHOBIC HATE IN THE COMPUTER ENVIRONMENT}

\begin{abstract}
The present study analyzed, through the theoretical method, the impacts that the discourse of homofóbico hatred brings to the computer environment. For this, the Information Society was explored as a new social paradigm. In the same way, the digital scope was investigated as a new category of the environment. Subsequently, the delimitations of the discourse of homophobic hate were presented, positioning it as a discursive act that violates the right to freedom of expression and drastically affects the experience of hetero-cis-discordant individuals. Finally, it has been shown that this discourse, when propagated in the digital environment, degrades its equilibrium and poluutes this space.
\end{abstract}

Key words: Hate speech; Homophobia; Computer environment.

\section{INTRODUÇÃO}

\footnotetext{
${ }^{1}$ Mestre em Ciências Jurídicas pelo Centro Universitário de Maringá (UNICESUMAR); Bacharel em Direito pela Universidade Estadual de Maringá (UEM); Advogado; E-mail: caio.cazelatto@hotmail.com ${ }^{2}$ Pós-doutora em Direito pela Universidade de Lisboa; Doutora e mestre em Direito das Relações Sociais pela Pontifícia Universidade Católica de São Paulo (PUCSP); Docente da Universidade Estadual de Maringá e no Programa de Pós-graduação em Ciências Jurídicas pelo Centro Universitário de Maringá (UNICESUMAR); Pesquisadora pelo ICETI; Advogada no Paraná; E-mail: valeria@galdino.adv.br
} 
O surgimento das tecnologias informáticas, sobretudo os computadores e a internet, acarretou um impacto na organização social, exigindo assim, uma nova postura jurídica frente as condutas praticadas no cenário virtual. Trata-se de um local repleto de interatividade, capaz de proporcionar aos seus usuários desde a comunicação, o entretenimento, a informação, até o trabalho. Essa conquista se deu em virtude da solidificação da Sociedade da Informação, que tem como principais símbolos a informação e a Grande Rede.

Por outro lado, o espaço informático acarretou conflitos inéditos à ordem jurídica, como o discurso do ódio homofóbico, que é ato discursivo intimidatório e de incitação ao ódio que, quando praticado no âmbito digital, afeta profundamente o equilíbrio dessa nova categoria do meio ambiente e os direitos fundamentais e de personalidade de seus usuários.

Trata-se de um discurso que, em inúmeras vezes, assume um aspecto velado e, em outras vezes, é perpetrado abertamente, mas que em ambos os casos são graves e merecem a adequada atenção e intervenção jurídica. Por ser uma conduta opressiva, preconceituosa e estigmatizadora, o discurso do ódio homofóbico cerceia o pleno exercício da sexualidade humana, na medida em que dificulta ou inviabiliza a vivência digna do indivíduo LGBT na sociedade, seja pela sua identidade sexual hetero-cisdiscordante, seja por fugir dos papéis e valores sexuais que são socioculturalmente padronizados e considerados dominantes. Em razão disso, reveste-se como um elemento poluidor do meio ambiente informático, já que cria uma condição imprópria ao bem estar e à segurança do usuário LGBT.

Hodiernamente, a temática ressurge com mais força, uma vez que ela incide na discussão dos limites da liberdade de expressão diante do ambiente virtual e da livre expressão sexual, especialmente pela intensa utilização das redes sociais, como Facebook, Twitter e Instragram.

Nesse contexto, surgem os seguintes questionamentos: a Sociedade da Informação representa o surgimento de um novo paradigma social e jurídico? O ambiente informático pode ser elencado como uma categoria de meio ambiente? Como se dá a sua tutela jurídica? Qual a sua conceituação e classificação? Seu equilíbrio representa um direito fundamental? No que se refere ao discurso do ódio homofóbico online, este é um violador de direitos de personalidade e fundamental de suas vítimas? 
Como o sentimento homofóbico pode ser exteriorizado? O discurso do ódio é um exercício da liberdade de expressão? Quais são as fronteiras entre a opinião, a expressão e o discurso do ódio? Como que o meio ambiente informático é afetado pelos atos discursivos de ódio homofóbico?

São essas indagações que a presente pesquisa buscará esclarecer por meio do método teórico, que consiste em analisar o que já foi produzido e registrado acerca do assunto, como obras doutrinárias, legislação, reportagens e documentos eletrônicos.

\section{DA SOCIEDADE DA INFORMAÇÃO COMO UM NOVO PARADIGMA SOCIAL}

Com o advento da revolução tecnológica do final do século $\mathrm{XX}$, assentada em um contexto pós-moderno, a utilização dos dispositivos informáticos, principalmente o computador conectado à internet, viabilizou a intensificação dos relacionamentos interpessoais, superando as barreiras territoriais dos Estados para uma rede de conexões em escala global. Essa ruptura na organização da sociedade está correlata com o exponencial avanço da ciência e da tecnologia e tem como sustentáculo a informática, a qual se reveste como imprescindível ao cotidiano dos seres humanos, propiciando o surgimento da Sociedade da Informação.

Essa nova configuração social é um fenômeno desencadeado, sobretudo, pelas três Revoluções Industriais, que tiveram como produtos, cronologicamente, a substituição do trabalho humano por máquinas, a criação da energia elétrica e o aprimoramento tecnológico, fatores, estes, que resultaram, na década de 1970, nos primeiros dispositivos informáticos aptos a estabelecerem a comunicação à distância, isto é, virtualmente (CRESPO, 2011, p. 32-33).

Segundo Manuel Castells, essa intensa mutação dos valores sociais pode ser denominada como um modelo informacional de desenvolvimento, já que está conexa com a circulação e a transformação da informação. Para ele, a evolução dos meios comunicacionais foi a responsável por romper drasticamente com o sistema políticoeconômico de épocas anteriores, valorizando a tecnologia e a informação como as principais fontes de produtividade e poder (CASTELLS, 1999, p. 411-439). 
A ideia de uma sociedade fundamentada profundamente na informação foi difundida no ambiente acadêmico pelo economista Fritz Machlup, em sua obra The Production and Distribution of Knowledge in the United States, publicada em 1966. O conceito desse arranjo social foi aprimorado, quase que simultaneamente, por Peter Drucker, em seu livro The Age of Discontinuit, também publicado em 1966, oportunidade em que trabalhou a influência da economia nos meios produtivos, especialmente como ocorreu com a transição dos meios de produção da agricultura para indústrias, das indústrias para os serviços e, mais recentemente, dos serviços para a informação (CRAWFORD, 1982, p. 380-385).

Apesar de comumente ser denominada por "Sociedade da Informação", Paulo Hamilton Siqueira Junior defende que essa terminologia ou qualquer outra similar é incabível, já que se trata de um arranjo social complexo e em constante mutação, transcendendo todas as formas de limitá-lo conceitualmente por meio de uma expressão única e verdadeira. Além disso, o autor aponta que a busca pelo conhecimento e pela informação sempre foram o centro da atenção humana, não justificando, novamente, a nomenclatura empregada (SIQUEIRA JUNIOR, 2007, p. 252-253).

Por outro lado, é inegável que a informática é o sustentáculo do atual modelo social, já que este está assentado em bens imateriais e estruturado em tecnologias que se relacionam com a produção, o processamento e a disseminação da informação por meio de instrumentos informáticos, razão pela qual o presente trabalho recorrerá à expressão "Sociedade da Informação".

A sociedade informacional é constituída, sobretudo, pela célere e ilimitada fonte de informação, a qual é veiculada por "[...] redes tecnológicas que fornecem novas capacidades a uma velha forma de organização social: as redes" (CASTELLS, 2005, p. 17), refletindo o produto das relações sociais hodiernas: a informação em meio virtual, desencadeando um novo paradigma, qual seja, a dependência das vivências humanas ao meio informático. Seus usuários o utilizam tanto para a comunicação e expressão de pensamentos, através de e-mails, redes sociais, bate-papos, torpedos, etc.; como para trabalhar, na modalidade do homeoffice; quanto para seu entretenimento, como: jogos online, vídeos, filmes, séries, etc. 
Verifica-se, nesse sentido, que essa configuração tem sua própria estrutura, seguindo limites morais e normativos específicos, como demonstra o sociólogo Niklas Luhmann:

\begin{abstract}
Toda sociedade, conforme sua própria complexidade, precisa prever um volume suficiente de diversidade de expectativas normativas, e possibilitá-la estruturalmente. Dessa forma é perfeitamente normal que projeções normativas conflitam uma com as outras, e que a norma de um torne-se o desapontamento do outro. A sociologia atual está plenamente capacitada para considerar como normais as contradições entre expectativas e até mesmo um grau tolerável de conflito declarado, reconhecendo isso até mesmo como uma condição para a manutenção do sistema social em um ambiente demasiadamente complexo (LUHMANN, 1983, p. 57).
\end{abstract}

Seguindo esse raciocínio, Manuel Castells alerta a necessidade de uma política inovadora fundamentada “[...] nas promoções das condições culturais e organizacionais para a criatividade na qual a inovação, o poder, a riqueza e a cultura se alicerçam, na sociedade em rede" (CASTELLS, 2005, p. 29). Isso porque, em consonância com o que sustenta S. Crawford, a participação social no meio digital está cada vez mais crescente e é usada como uma potente ferramenta política, afetando drasticamente seus aspectos jurídicos, sociais e culturais (CRAWFORD, 1983, p. 382).

Em meio ao paradoxo da concentração do poder político, econômico e social na informação, Severino Francisco aponta o surgimento do que ele intitula por Sociedade da Desinformação, a qual é estruturada, principalmente, em conteúdos distorcidos, falsos e dissimulados no ambiente digital. Nessa perspectiva, o autor faz diversas críticas a essa configuração social, como a falta de leitura, a preocupação tão somente com o entretenimento, como também a massificação de seus usuários a conteúdos de senso comum, isto é, de baixo teor educacional e científico. Para ele, “[...] as tecnologias da informação precisariam agregar valores éticos, educacionais, sociais, humanistas, culturais, artísticos e espirituais" (FRANCISCO, 2004).

Se por um lado o espaço informático se solidificou como uma fonte ilimitada de conhecimento, reinventando a concepção de cidadania, de linguagem e de espaço, por outro se tornou um recipiente de informações vazias e, até mesmo, de condutas preconceituosas e discriminatórias, como no caso do discurso de ódio homofóbico. Embora seja um espaço que não é físico, os atos nele praticados produzem efeitos 
materiais, inclusive os de cunho lesivo a direitos de personalidade, razão pela qual é necessária uma maior explanação sobre a estruturação desse ambiente informático.

\section{DOS ASPECTOS JURÍDICO-CONSTITUCIONAIS DO AMBIENTE INFORMÁTICO}

O primeiro respaldo constitucional atribuído ao meio ambiente (em sentido amplo) se deu através do art. 225, do Capítulo VI, do Título VIII - Da Ordem Social, da Constituição Federal de 1988, oportunidade em que foi elencado como um direito fundamental, tendo em vista ser de uso comum das pessoas e essencial à sadia qualidade de vida da coletividade. A sua tutela jurídica teve como finalidade a proteção dos recursos e valores ambientais, visando a sua qualidade e o seu equilíbrio, como também a saúde, o bem-estar e a segurança da população nele inserida (SILVA, J., 2003, p. 78).

Apesar de ser um bem trivial à humanidade, a legislação pátria atribuiu um conceito restrito ao termo "meio ambiente", limitando-o ao "[...] conjunto de condições, leis, influências, alterações e interações de ordem física, química e biológica, que permite, abriga e rege a vida em todas as suas formas". ${ }^{3}$ No entanto, é necessário flexibilizar essa definição, buscando sempre englobar as constantes mutações e necessidades sociais, culturais e axiológicas.

Para sanar a carência legislativa sobre o tema, José Joaquim Gomes Canotilho defende que o meio ambiente pode ser descrito como o "[...] conjunto dos elementos que, na complexidade das suas relações, constituem o quadro, o meio e as condições de vida do indivíduo, tal como são, ou tal como são sentidos" (CANOTILHO, 1995, p. 10). Acrescenta José Afonso da Silva que se trata de um bem jurídico responsável pela “interação do conjunto de elementos naturais, artificiais e culturais que propiciem o desenvolvimento equilibrado da vida em todas as suas formas" (SILVA, J., 1998, p. 19).

Seguindo esse raciocínio, Celso Antonio Pacheco Fiorillo assevera que o art. 225, da Constituição Federal possui um enfoque biocêntrico/antropocêntrico, direcionado à satisfação das necessidades humanas, o que pressupõe que sua delimitação não deve ser rígida ou estática, uma vez que o ser humano é o titular do direito à equilibrada qualidade de vida no meio o qual está inserido, seja este qual for.

${ }^{3}$ Cf. art. $3^{\circ}$, I, da Lei n. 6.938/81 (BRASIL, 1981). 
Dessa forma, é possível classificar o meio ambiente não apenas pelos elementos da natureza ${ }^{4}$, como a fauna e a flora, mas também por toda construção e relação social, como é o caso do meio ambiente artificial $^{5}$, do trabalho $^{6}$ e, especialmente, do cultural, do qual advém o espaço informático.

Para se analisar o meio digital, convém explorar mais detalhadamente o ambiente cultural, tendo em vista que nele reside a sua gênese conceitual. $\mathrm{O}$ ambiente cultural está previsto no art. 216, incisos IV e V, da Lei n. 6.938/81 e no art. 216, da Constituição Federal, destacando-se por abarcar, de modo não taxativo, as criações humanas, como o patrimônio histórico, arqueológico, artístico, turístico, paleontológico, paisagístico, ecológico e científico. Essa categoria consiste nas intervenções humanas materiais ou imateriais detentoras de valor cultural referente à identidade, à ação e à memória dos diferentes grupos formadores de nacionalidade brasileira.

Reforça Paulo Affonso Leme Machado que o ambiente cultural é detentor das características de um povo, como a sua formação, a sua cultura e os seus demais caracteres definidores de suas especificidades (MACHADO, 2006, p. 1081), oportunidade em que se podem incluir as inovações tecnológicas comunicacionais, como o espaço digital, conforme complementa Celso Antonio Pacheco Fiorillo:

[...] os diversos veículos reveladores de um novo processo civilizatório adaptado necessariamente à sociedade da informação, a saber, de uma nova forma de viver relacionada a uma cultura de convergência em que as emissoras de rádio, televisão, o cinema, os videogames, a internet, as comunicações por meio de telefones fixos e celulares etc. moldam uma "nova vida" reveladora de uma nova faceta do meio ambiente cultural, a saber, o meio ambiente digital (FIORILLO, 2015, p. 53).

Com similar compreensão, Ricardo Cavedon et. al. ressaltam que são os mesmos de comunicação que sustentam o espaço digital, destacando que essa recente

\footnotetext{
${ }^{4} \mathrm{O}$ espaço natural é um dos espaços que engloba os recursos naturais como: “[...] a atmosfera, as águas interiores, superficiais e subterrâneas, os estuários, o mar territorial, o solo, o subsolo, os elementos da biosfera, a fauna e a flora", conforme preceituam o art. $3^{\circ}$, inciso V, da Lei n. 6.938/81, como também o art. $225, \S 1^{\circ}$, incisos I, II, III e IV, da Constituição Federal.

5 O meio ambiente artificial pode ser compreendido por aquele construído pelo ser humano em substituição dos espaços naturais, como as construções urbanísticas e rurais, encontra-se amparado no art. 21, inciso XX, da Lei n. 6.938/81, e art. 182, da Constituição Federal.

${ }^{6} \mathrm{O}$ meio ambiente do trabalho, regulamentado pelos arts. $7^{\circ}$, incisos XXII e XXIII, e 200, inciso VIII, da Constituição Federal, Amauri Mascaro Nascimento assinala ser um espaço estruturado pelo complexo entre máquina e trabalhador, isto é, constitui-se pelas instalações edificadas, instrumentos de uso individual, condições de salubridade, periculosidade, jornada de trabalho, férias, relação entre empregado e empregador, entre outros fatores (NASCIMENTO, 2011, p. 846).
} 
categoria emergiu do "[...] do reconhecimento constitucional de que as formas de expressão, os modos de criar, fazer e viver e as criações científicas, artísticas e tecnológicas constituem ou integram o patrimônio cultural brasileiro", razão pela qual, tem-se que o meio ambiente digital como "[...] parte indissociável do conceito jurídico de meio ambiente trazido pelo art. $3^{\circ}$ da Lei 6.938/1981, manifestando-se inequivocamente por meio da sua dimensão cultural" (2015, p. 203-204).

Nesse contexto, o ambiente informático deve ser compreendido como uma extensão do âmbito cultural, podendo ser explorado como o canal de manifestações multiculturais, em que o ser humano, a partir da internet e dos instrumentos informáticos, como celulares, tablets, notebooks, etc, realiza seu processo social de criação e manipulação de símbolos.

Com o reconhecimento do meio ambiente (em sentido amplo) como um direito fundamental, novos valores passaram a sustentar esse instituto, atribuindo o dever de defesa e de proteção desse bem a todos os seres humanos, especialmente ao que se referir ao seu equilíbrio, visando preservar a sua função social. Isso é plenamente aplicável ao meio ambiente informático, em que todos os indivíduos são, direta ou indiretamente, titulares de:

[...] deveres, direitos, obrigações e regimes de responsabilidades inerentes à manifestação do pensamento, criação, expressão e informação realizados pela pessoa humana com a ajuda de computadores (Art. 220 da Constituição Federal) dentro do pleno exercício dos direitos culturais assegurados a brasileiros e estrangeiros residentes no País (FIORILLO, 2015, p. 23).

Trata-se de atribuir ao espaço digital uma nova perspectiva de respeito, de proteção e de promoção, emergindo o dever de mantê-lo sadio e equilibrado, tendo em vista que "o direito fundamental ao meio ambiente ecologicamente equilibrado é elemento importante para obtenção de padrões de vida digna e saudável” (FIORILLO, 2004, p. 328).

Garantir o equilíbrio do ciberespaço, ao qual a coletividade executa suas atividades mais básicas, representa, de fato, proteger a vida, a igualdade, a liberdade e a dignidade coletiva e tantos outros direitos fundamentais e de personalidade de seus usuários (CAZELATTO; MORENO, 2016, p. 153-154). Portanto, ao desrespeitar o equilíbrio, a estrutura ou qualquer outro elemento que integra o meio ambiente 
informático, tanto este instituto, assim como diversos direitos correlatos a ele serão violados.

Nesse sentido, sustenta Luciane Mascarenhas que:

\begin{abstract}
O meio ambiente equilibrado traz, portanto, uma nova dimensão ao direito fundamental à vida e ao princípio da dignidade da pessoa humana, visto que, no meio ambiente se desenvolve a vida humana. Assim, o ser humano está inserido no meio ambiente, dele também fazendo parte, motivo pelo qual, para que haja efetividade ao direitos fundamental à vida e ao princípio da dignidade humana, há que reconhecer a sua ligação e a interação com o meio ambiente e que ele seja ecologicamente equilibrado, a fim de propiciar o bem-estar necessário (MASCARENHAS, 2008, p. 53-54).
\end{abstract}

Um dos fatores que afeta o espaço digital é o discurso de ódio homofóbico, que ao ser propagado em redes sociais, e-mails, aplicativos de celulares, etc, incitando o preconceito, a discriminação e a intimidação a outrem, irradiando efeitos danosos aos direitos de seus usuários, especialmente às minorias sexuais, causa uma desordem ao ambiente informático, já que são condutas que se materializarão na vida real, isto é, fora das telas dos dispositivos computacionais, como ocorre com os crimes de ódio.

\title{
4 DO DISCURSO DE ÓDIO HOMOFÓBICO
}

Com a complexidade e o estreitamento das relações individuais impulsionados, principalmente, pelas tecnologias informativas, a linguagem se potencializou como um instrumento de poder sobre o controle social, emergindo questões antes não antevistas ou pouco discutidas, como os limites da liberdade de expressão. Liberdade, esta, que permite as pessoas a se socorrerem à comunicação e à propagação de seus pensamentos, mas também possibilita à utilização de atos discursivos de ódio, razão pela qual a sua análise transcende a mera interpretação exegética da lei, para se aprofundar na interpretação dos valores assegurados constitucionalmente, como a liberdade, a tolerância, a igualdade, a dignidade e a não discriminação.

Considerado como uma ferramenta de reprodução de ideologias, o discurso de ódio tem suas raízes na terminologia americana hate speech, podendo ser caracterizado como um instrumento que se utiliza da linguagem verbal ou extraverbal, como a fala, os gestos, a música, o cinema, o vídeo, a pintura, a dança, os livros e até o silêncio para transmitir as manifestações de desprezo, de intolerância e de violência (SARMENTO, 
2006, p. 208). Em outras palavras, é um ato de incitação ao ódio, carregado com um conteúdo hostil contra determinados grupos, geralmente contra grupos vulneráveis ou minorias sociais, motivadas por preconceitos ligados à etnia, à religião, à idade, à condição financeira, à orientação afetivo-sexual, à identidade de gênero, dentre tantos outros (BRUGGER, 2007, p. 151).

São manifestações do pensamento que buscam transmitir e alimentar o ódio, devalorizando, menosprezando, desqualificando e inferiorizando o ser humano à condição de objeto. Em suma, essas atitudes insuflam o desrespeito pelo diferente. De fato, o ódio social não é apenas o motivo de conflitos entre os indivíduos isoladamente considerados, mas também em sua coletividade, organizados em grupos, em classes ou mesmo enquanto sociedade, caracterizando-se por sua essência de repulsa advinda de razões sociais (SILVEIRA, 2007, p. 80-82). É um sentimento que se direciona para além de sua vítima, já que visa disseminar a cultura do medo e do terror para alcançar indivíduos que, ou coadunem com esse posicionamento ou que se sintam ameaçados (MEYER-PLUFG, 2014, p. 386).

Assim, a caracterização do discurso do ódio decorre, como dispõe Alexandre Assunção e Silva, da transgressão dos limites da liberdade de expressão, seja pelo não respeito às restrições impostas expressa ou implicitamente pela Constituição Federal, seja pelo abuso do seu exercício, carregando-o com um conteúdo que vai além da finalidade desse direito (SILVA, A., 2012, p. 37-43).

Em virtude do subjetivismo que perpassa a identificação do discurso de ódio, seus limites com a liberdade de expressão se demonstram, em muitos casos, sutis, dificultando a percepção de seu aspecto agressivo. De acordo com Meyer-Plufg, este pode ocorrer de modo implícito, velado ou subliminar, também denominado por discurso material, ou de maneira explícita, clara e aparente, também qualificado como discurso formal (MEYER-PLUFG, 2011).

Em que pese a legislação brasileira carecer de uma regulamentação acerca do discurso de ódio, uma das diretrizes para a sua identificação pode se dar por meio do Pacto Internacional sobre Direitos Civis e Políticos, o qual aponta alguns critérios para distinguir o discurso de ódio do simples exercício da liberdade de expressão, quais sejam: conter severa ofensa; possuir a intenção de incitar o ódio; ter a forma de um discurso; ser dirigido ao público em geral ou a um número de indivíduos em um espaço 
público; conter a probabilidade de ocorrência de dano; ser um dano iminente, visando a possibilidade de identificar a ação e imputar ao emissor do discurso a responsabilidade pelo eventual resultado; e, por fim, estar inserido em um contexto que possibilita verificar se as declarações tem potencial de incitar ódio e gerar alguma ação (BRASIL, 1992).

Para que esse ódio produza efeitos lesivos é necessária a sua externalidade, isto é, sair do plano abstrato do pensamento para o espaço público, o que se dá por meio do discurso (SILVA, R., 2011, p. 447). Logo, a questão fundamental que permeia essa conduta discursiva é a relação entre o pensar, o falar e o agir. Nessa perspectiva, sua concretização pressupõe a sua publicidade, caso contrário, serão apenas pensamentos, sentimentos e ódio sem o discurso, o que tornaria incabível a sua intervenção através de sanções jurídicas ou extrajurídicas.

Sob o ponto de vista jurídico, há duas correntes doutrinárias opostas, uma que defende o hate speech como um livre desenvolvimento do direito à liberdade de expressão, outra como abuso deste direito. Seguindo a primeira vertente, Raoul Vaneigem compreende o livre e o amplo exercício da manifestação de expressão como o direito de se expressar a respeito de qualquer assunto, justificando-se que seus limites serão impostos pelos seus receptores, que deverão avaliar e concordar ou não com o que foi transmitido, razão pela qual essa liberdade não deve ter restrições:

\footnotetext{
Autorizem-se todas as opiniões; nós saberemos reconhecer as nossas, nós aprenderemos a anular a força atrativa dos males, a impedir que a corrupção do lucro e do poder insista em gangrenar as mentalidades, nós as combateremos pela única crítica que pode erradica-las: pensando por nós mesmos (VANEIGEM, 2004, p. 99).
}

Com similar compreensão, John Stuart Mill aponta que todo arranjo social é dirigido, para fins organizacionais e de ordem, por determinadas "verdades", isto é, por postulados aceitos pela (tirania da) maioria. Em conformidade com essa teoria, ao se proteger o direito de se exteriorizar livremente novas "verdades" perante as anteriores, a liberdade de expressão se qualifica como um dever social, tendo em vista que tais são apresentados ao crivo do público para a análise de seus conteúdos. Caso forem coerentes, as pessoas as aceitarão, caso contrário, serão repudiadas, pelo que se justifica nunca censurar esse direito (MILL, 1992, p. 58-61). Em outras palavras, em um 
mercado livre de ideias, as opiniões verdadeiras irão encontrar o apoio da sociedade e prevalecerão sobre as falsas.

Apesar de ser um defensor radical da liberdade, sustentando, inclusive, que o indivíduo deve ser livre para causar danos a si mesmo, John Stuart Mill revela uma única e específica hipótese para limitá-la: a possibilidade de causar danos a outrem, especialmente em casos da liberdade de expressão de um limitar a do outro. Trata-se da aplicação do que ele denomina por harm principle (MILL, 1992, p. 60).

Para Ronald Dworkin, as manifestações de expressão que são consideradas ofensivas e detentoras de repúdio por parte da sociedade têm tanto direito de proteção jurídica quanto qualquer outra expressão, isso porque, para ele, os discursos, não importam quais sejam, devem ser combatidos com mais discursos, para que aquele que melhor for argumentado se sobressaia sobre os demais, não necessitando de outras intervenções, como as limitações jurídicas da liberdade de expressão (DWORKIN, 2006, p. 321).

Sob a mesma ótica, Alexandre Assunção e Silva sustenta a manutenção do direito de tudo poder pensar e dizer como um mecanismo de combate às condutas ofensivas e de tiranias à humanidade, tendo em vista que só com a liberdade de expressão é que estas poderão ser devidamente denunciadas e combatidas (SILVA, A., 2012, p. 11-12).

Para Antonio de Holanda Cavalcante Segundo, é necessário conferir a prevalência a priori à liberdade de expressão, inclusive quando praticada enquanto um discurso de ódio em face de outros direitos ou valores, tendo em vista que, quando se limita esse direito, corre-se o risco de que a exceção se torne a regra, dando espaço à censura (CAVALCANTE SEGUNDO, 2016, p. 118).

No entanto, ressaltam Maria Lúcia de Arruda Aranha e Maria Helena Pires Martins que, ao ser repetidamente expostos, os discursos carregados de conteúdos falsos ou até mesmo preconceituosos podem acabar sendo aceitos, equivocadamente, como verdadeiros, distanciando do que propunham os ativistas da livre e aberta atividade de expressão (ARANHA, 2009, p. 125).

A segunda corrente, favorável à restrição da liberdade de expressão, tem como um de seus expoentes Daniel Sarmento, o qual sustenta que o discurso de ódio não deve ser o meio adequado para a obtenção de respostas relacionadas a problemas que afligem 
a sociedade, uma vez que tal representa mais um ato hostil do que um de cunho discursivo informativo:

Diante de uma manifestação de ódio, há dois comportamentos prováveis da vítima: revidar com a mesma violência, ou retirar-se da discussão, amedrontada e humilhada. Nenhum deles contribui minimamente para "a busca da verdade" (SARMENTO, 2006, p. 236).

Dessa forma, ao se constatar as expressões de ódio, intolerância e preconceito manifestadas na esfera pública ou privada, mesmo quando essas estiverem sob o manto da busca da verdade e do conhecimento, é recomendável, na visão do supracitado autor, a sua proibição. De fato, o discurso em sentido estrito não deve ser considerado como a simples liberdade de expor "o que quiser". Ele é uma ação com viés comunicativo que, quando assume ênfase no ato de desvalor da vítima, deixa de ser uma mera opinião, configurando-se como um discurso de incitação ao ódio, já que acarreta efeitos materiais lesivos a seus destinatários.

Para José Emílio Medauar Ommati, ao buscar negar direitos fundamentais, o discurso de ódio deixa de ser uma liberdade de expressão, razão pela qual é incabível a discussão acerca dos limites desse direito (OMMATI, 2016, p. 20-21).

Uma das minorias sociais mais afetadas pelo discurso de incitação ao ódio é a sexual. Apesar da história da humanidade ser marcada pela constate construção e desconstrução dos valores sexuais, hodiernamente prevalecem os fundamentos heteronormativos na condução do exercício da sexualidade humana, os quais são veiculados por meio do discurso de ódio homofóbico, que visam impor “[...] uma lógica inteligível que tenta definir o certo e o errado, o são e o patológico, o pecaminoso e o santificado" (NASCIMENTO, 2010, p. 236).

Ocorre que, em inúmeras vezes, tal discurso assume um aspecto velado, como no caso de piadas ou de programas humorísticos que ridicularizam a identidade LGBT, e, em outras vezes, é perpetrado abertamente, como no caso dos discursos do deputado federal Jair Messias Bolsonaro, o qual incita, por exemplo, o estupro corretivo ${ }^{7}$, bem como a segregação das minorias sexuais (EXAME, 2016), mas que ambas as hipóteses são graves e merecem as adequadas atenção e intervenção estatal.

\footnotetext{
${ }^{7} \mathrm{O}$ estupro corretivo é uma conduta ilícita, em que uma ou mais pessoas estupram mulheres homossexuais, bissexuais ou indivíduos transgêneros, visando, supostamente, "curá-los" de suas sexualidades heto-cis-discordantes.
} 
Para identificar uma expressão homofóbica deve ser analisado seu cometimento com base na motivação a partir de características de grupos LGBT, em que mesmo que o ataque seja direcionado a uma única pessoa, quando o fator de motivação do agente for o sentimento homofóbico, isto é, aversão aos papéis culturais atribuídos ao sexo, ao gênero, à identidade de gênero e à orientação afetivo-sexual, este ato não será um mero insulto pessoal, mas, sim, um discurso de ódio de cunho homofóbico, já que irradia seus efeitos a uma gama de vítimas.

\section{DOS IMPACTOS DO DISCURSO DE ÓDIO HOMOFÓBICO NO AMBIENTE DIGITAL}

A internet conectada aos dispositivos computacionais assume um ambiente propício à propagação de condutas de diversas naturezas, sendo que algumas delas são capazes de produzir a vitimização tanto individual quanto em massa. É nesse contexto que se apresenta o discurso de ódio homofóbico no meio ambiente informático.

Segundo a Secretaria de Comunicação Social da Presidência da República, por meio da Pesquisa Brasileira de Mídia 2015, praticamente a metade dos brasileiros, isto é, 48\%, usa internet (BRASIL, 2015). O percentual de pessoas que a utilizam diariamente cresceu de $26 \%$ em 2014 para 37\% em 2015. Os usuários das novas mídias ficam conectados, em média, $4 \mathrm{~h} 59 \mathrm{~min}$ por dia durante a semana e $4 \mathrm{~h} 24 \mathrm{~min}$ nos finais de semana. Desse percentual, $92 \%$ dos internautas estão conectados por meio de redes sociais, sendo as mais utilizadas o Facebook (83\%), o Whatsapp (58\%) e o Youtube (17\%) (BRASIL, 2015).

Trata-se de um significativo número de usuários aos quais os instrumentos informáticos estão indissociáveis de seus cotidianos. Evidentemente, quanto mais utilizado ele é, maiores são as chances do cometimento de atos discursivos de ódios e de outros ilícitos, fortalecendo a apologia ao ódio, como elucida Rosane Silva et. al:

Quando uma pessoa dirige um discurso de ódio a outra, a dignidade é vulnerada em sua dimensão intersubjetiva, no respeito que cada ser humano deve ao outro. Mas não só isso. No caso do discurso odiento, vai-se além: é atacada a dignidade de todo um grupo social, não apenas a de um indivíduo. Mesmo que este indivíduo tenha sido diretamente atingido, aqueles que compartilham a característica ensejadora da discriminação, ao entrarem em contato com o discurso odiento, compartilham a situação de violação. 
Produz-se o que se chama de vitimização difusa. Não se afigura possível distinguir quem, nominal e numericamente, são as vítimas. Aquilo que se sabe é que há pessoas atingidas e que tal se dá por conta de seu pertencimento a um determinado grupo social (SILVA, R., 2011, p. 449).

Isso se dá, principalmente, em virtude do agente propagador da ideologia dominante e hostil que, de certa forma, sente-se protegido pela tela dos computadores e, em diversas vezes, pelo anonimato que a grande rede propicia. É essencial contextualizar esse fenômeno considerando sua exteriorização, como por exemplo, a criação de perfis falsos, a utilização de dados pessoais da vítima, a violação de senhas, a invasão de dispositivos informáticos, os xingamentos, as piadas e os comportamentos de humilhação, bem como considerar o meio onde ocorre, como: sites de redes sociais, emails, torpedos SMS, aplicativos de celulares, dentre outros. São condutas direcionadas à disseminação do preconceito, da intolerância e da segregação, que ao serem inseridos nos meios digitais ganham uma amplitude ilimitada e um maior grau de violação de direitos de suas vítimas.

Para Erick Felinto, esse novo espaço da convivência humana é responsável pela armazenagem virtual inesgotável de detritos culturais, de restos, de informações inúteis e triviais, isto é, de elementos que além de não serem úteis aos internautas, também os deixa poluído, impróprio para navegação (FELINTO, 2007, p. 34).

Ressalte-se que a concepção de poluição ambiental, prevista no art $3^{\circ}$, inc. III, da Lei n. 6.9238/81, conhecida por Lei da Política Nacional do Meio Ambiente, é elástica, delimitando-a como a degradação do meio ambiente resultante das atividades que prejudiquem a saúde, a segurança e o bem estar da população, como também que criem condições adversas às relações sociais e econômicas, afetando as suas condições estéticas ou sanitárias.

A respeito do assunto, Eduardo Carlos Bianca Bittar (2014, p. 95-96) aponta para o fato de que a internet pode ser utilizada como instrumento eficaz de divulgação de:

[...] ações antissociais, manifestadas pelo bullying virtual, pela pedofilia transfonteiriça, pela facilitação do tráfico internacional de pessoas, pela divulgação de doutrinas neonazistas, discursos de ódio (hate speech), expressões de racismos e perseguições a minorias, pelo fortalecimento de redes de crime organizado, pela facilitação massiva da contrafação e da violação de direitos de propriedade intelectual. 
Assim, qualquer informação ou conduta, a depender da sua finalidade, que sejam empregadas virtualmente podem corresponder a uma poluição digital, isto é, ao digital trash. É o que ocorre com o discurso de ódio homofóbico e tantos outros atos que desequilibram a harmonia do espaço digital, já que, ao estimular a homofobia, cria condições adversas aos usuários tidos como minorias sexuais, colocando em risco o bem estar e a segurança desse público.

Isso ocorre porque o discurso homofóbico além de ser um ato discursivo vazio de conteúdo moral, afeta a vivência e a diversidade sexual das minorias sexuais, transformando-as em indivíduos-objetos, tendo em vista que, ao ser pouco a pouco difundido e assimilado como correto e coerente, reforça a intolerância contra a diversidade sexual nos diversos âmbitos institucionais do sujeito, como na família, na escola, no trabalho, instigando implícita ou explicitamente a violência na forma dos crimes de ódio.

Nesse sentido, Francielle Lopes Rocha e Valéria Silva Galdino Cardin sustentam que o discurso homofóbico é um instrumento de exclusão social perante aqueles que transpõem as barreiras do modelo hetero-cisnormativo, razão pela qual sofrem com a discriminação, o preconceito e a exclusão social. ${ }^{8}$

Portanto, é dever o Estado e de todas as pessoas pessoa adotar de medidas preventivas e sustentáveis perante o ambiente digital, visando não somente evitar sua degradação, mas também proteger os diversos direitos fundamentais dos indivíduos que estão nele vinculados, como o das minorias sexuais, uma vez que, de acordo com a Secretaria de Direito Humanos do Ministério da Justiça e Cidadania, por meio do último Relatório de Violência Homofóbica no Brasil, no ano 2013 ao menos cinco casos de violência homofóbica foram registrados todos em território nacional (BRASIL, 2013), englobando, inclusive, aqueles cometidos no meio informático.

Esses números, por mais assustadores que pareçam, ainda não refletem a realidade, tendo em vista que a maioria desse tipo de ilícito é classificada e registrada pelos órgãos competentes como crimes comuns, sem o viés homofóbico. Há, ainda,

\footnotetext{
${ }^{8}$ ROCHA, Francielle Lopes; CARDIN, Valéria Silva Galdino. Do discurso do ódio contra as minorias sexuais como um instrumento de exclusão social. In: SIQUEIRA, Dirceu Pereira; AMARAL, Sérgio Tibiriça (org.). Democracia, Liberdade e Justiça Social: Fundamentos para uma teoria jurídica do reconhecimento. Biriqui: Boreal, 2015, p. 193.
} 
aqueles delitos sexuais que sequer são comunicados ao Poder Público, ficando perdidos na cifra negra.

Dessa maneira, garantir que esse ambiente seja livre de qualquer risco, ameaça ou prejuízo na navegação online, como o discurso de ódio, é garantir o respeito e a proteção do direito à vida, à saúde, à liberdade, à vida privada e, especialmente, à liberdade sexual livre de preconceitos e/ou discriminação.

Além disso, a preservação do espaço virtual é um interesse coletivo, em que promover seu desenvolvimento sustentável, por meio dos controles público e privado, como o combate ao discurso de ódio homofóbico bem como garantir a segurança de seus usuários, é estabelecer um ponto de equilíbrio para sua preservação.

\section{CONSIDERAÇÕES FINAIS}

Conclui-se que os dispositivos informáticos surgiram para suprir a necessidade básica do ser humano de potencializar sua capacidade e extensão comunicativa, modificando a concepção das relações sociais, econômicas, culturais e políticas, as quais passaram a se articular em rede, solidificando o que se concebe como Sociedade da Informação.

Esse novo arranjo social foi profundamente marcado pelas revoluções tecnológicas, especialmente as Industriais, rompendo, como dispõe a teoria do informacionalismo, drasticamente com épocas anteriores e impondo um novo paradigma social baseado na informação e nas tecnologias informáticas.

Trata-se de uma reorganização estrutural da sociedade baseada em noções de limites territoriais, morais, normativas e de conhecimento próprios, razão pela qual se reveste como uma nova categoria de meio ambiente, originada como uma extensão do ambiente cultural, já que, assim como este, o ciberespaço é detentor do patrimônio cultural de um povo, como também um produto da criação humana, com aspectos múltiplo, vivo e mutante, sendo repleto de particularidades, merecendo uma tutela jurídica própria e específica.

Apesar das ferramentas informáticas serem essenciais ao cotidiano do ser humano, viabilizando a troca de informações, a liberdade de expressão, o lazer, a educação, o trabalho e o comércio, bem como se configurando um mecanismo 
facilitador do exercício dos direito civis, sociais e políticos, constatou-se, por outro lado, que o espaço digital é propício à prática de diversos ilícitos e condutas danosas aos usuários do espaço informático, como o discurso de ódio homofóbico.

Estes são atos discursivos intimidatórios e de incitação ao ódio que se escondem atrás do exercício de liberdade de expressão, mas nada mais é do que um abuso deste direito, que está, portanto, muito distante de uma mera opinião, tendo em vista que resultam em efeitos lesivos às minorias sexuais, bem como poluem o ambiente informático, afetando direta ou indiretamente o seu equilíbrio.

\section{REFERÊNCIAS}

ARANHA, Maria Lúcia de Arruda; MARTINS, Maria Helena Pires. Filosofando: Introdução à Filosofia. 4. ed. São Paulo: Moderna, 2009.

BRASIL. Decreto n. 592, de 6 de julho de 1992: Pacto Internacional sobre Direitos Civis e Políticos. 1992. Disponível em: <www.planalto.gov.br/ccivil_03/decreto/19901994/d0592.htm>. Acesso em: 17 fev. 2017.

Lei $n$. 6.938, de 31 de agosto de 1981. 1981. Disponível em:

$\overline{<\mathrm{http}: / / w w w . p l a n a l t o . g o v . b r / c c i v i l[03 / L e i s / L 6938 . h t m>. ~ A c e s s o ~ e m: ~} 09$ abr. 2016.

, Secretaria de Comunicação Social da Presidência da República. Pesquisa Brasileira de Mídia 2015. 2015. Disponível em:

<http://www.secom.gov.br/atuacao/pesquisa/lista-de-pesquisas-quantitativas-equalitativas-de-contratos-atuais/pesquisa-brasileira-de-midia-pbm-2015.pdf > . Acesso em: 20 set. 2016.

, Secretaria de Direito Humanos do Ministério da Justiça e Cidadania. 2013. Relatório de Violência Homofóbica no Brasil: ano 2013. Disponível em: <www.sdh.gov.br/assuntos/lgbt/dados-estatisticos/Relatorio2013.pdf>. Acesso em: 20 set. 2016

BRUGGER, Winfried. Proibição ou proteção do discurso do ódio? Algumas observações sobre o direito alemão e o americano. Revista de Direito Público, Brasília, v. 15, n. 117, jan.-mar. 2007.

CANOTILHO, José Joaquim Gomes. Protecção do Ambiente e Direito de Propriedade (crítica de jurisprudência ambiental). Coimbra: Coimbra Editora, 1995.

CARDIN, Valeria Silva Galdino; SEGATTO, Antonio Carlos; CAZELATTO, Caio Eduardo Costa. O exercício ilegítimo do discurso de ódio homofóbico sob a ótica da 
sexualidade e da dignidade humana. Revista Jurídica - Unicuritiba, v. 1, n. 46, p. 90118, 2017. Disponível em:

<revista.unicuritiba.edu.br/index.php/RevJur/article/view/2001>. Acesso em: 10 jul. 2017.

CAVALCANTE SEGUNDO, Antonio de Holanda. Uma questão de opinião?

Liberdade de expressão e seu âmbito protetivo: da livre manifestação do pensamento ao Hate Speech. Rio de Janeiro: Lumen Juris, 2016.

CAVEDON, Ricardo. FERREIRA, Heline Sivini e FREITAS, Cinthia Obladen de Almendra. O meio ambiente digital sob a ótica da Teoria da Sociedade de Risco: os avanços da informática em debate. Revista Direito Ambiente e Sociedade, v. 5, n. 1, 2015. Disponível em:

<http://www.ucs.br/etc/revistas/index.php/direitoambiental/article/view/3912/2318>. Acesso em: 17 abr. 2017.

CAZELATTO, Caio Eduardo Costa; MORENO, Michel Henrique Timóteo. Da Sociedade da Informação frente ao Acesso à Internet como um Direito Fundamental de Personalidade. In: Anais XXV Encontro Nacional do Conpedi, 2016, p. 152-172, BRASÍLIA/DF. Disponível em: < http://www.conpedi.org.br/publicacoes/y0ii48h0/k778x2oo/zgqAj9dBszMD3c0L.pdf $>$. Acesso em: 26 set. 2016.

; SEGATTO, Antonio Carlos. Dos crimes informáticos sob a ótica do meio ambiente digital constitucionalizado e da Segurança da Informação. Revista Jurídica Cesumar - Mestrado, v. 14, n. 2, p. 387-411, jul./dez. 2014. Disponível em: <http://periodicos.unicesumar.edu.br/index.php/revjuridica/article/view/3713/2469>. Acesso em: 23 jul. 2017.

; CARDIN, Valéria Silva Galdino. Homophobic hate discourse in the information society: from the impacts to the balance of the computer environment and to human sexuality. Revista do Direito, Santa Cruz do Sul, v. 1, n. 51, p. 176-191, jan. 2017. ISSN 1982-9957. Disponível em: <https://online.unisc.br/seer/index.php/direito/article/view/8742>. Acesso em: 23 jul. 2017.

O discurso de ódio homofóbico no Brasil: um instrumento limitador da sexualidade humana. Revista Jurídica Cesumar - Mestrado, v. 16, n. 3, p. 919-938, set./dez. 2016. Disponível em:

<periodicos.unicesumar.edu.br/index.php/revjuridica/article/view/5465/2893>. Acesso em: 19 jun. 2017.

CRAWFORD, S.. The origin and development of a concept: the information society. Bull. Med. Libr. Assoc.. 71(4), 1983, p. 380-385. Disponível em: 
<http://www.ncbi.nlm.nih.gov/pmc/articles/PMC227258/pdf/mlab00068-0030.pdf.>. Acesso em: 12 nov. de 2015

DWORKIN, Ronald. $O$ direito da liberdade: A leitura moral da Constituição norte americana. São Paulo: Martins Fontes, 2006.

EXAME. Jair Bolsonaro reforça homofobia em entrevista a Ellen Page. 2016. Disponível em: <exame.abril.com.br/brasil/jair-bolsonaro-reforca-homofobia-ementrevista-a-ellen-page/>. Acesso em: 12 fev. 2017.

FELINTO, Erick. Videotrash: O YouTube e a Cultura do "spoof" na internet. In: XVI COMPÓS, 2007, Curitiba. Anais da XVI Compós, Curitiba, 2007.

FIORILlO, Celso Antonio Pacheco. Curso de direito ambiental brasileiro. 5. ed. São Paulo: Saraiva, 2004.

Princípios constitucionais do direito da sociedade da informação: a tutela jurídica do meio ambiente digital. São Paulo: Saraiva, 2015.

MACHADO, Paulo Affonso Leme. Direito Ambiental Brasileiro. São Paulo: Malheiros, 2006.

MASCARENHAS, Luciane Martins de Araújo. Desenvolvimento sustentável: estudo de impacto ambiental e estudo de impacto de vizinhança. Curitiba: Letras da Lei, 2008.

MEYER-PLUFG, Samantha Ribeiro. Ideias devem ser confrontadas com ideias. Revista Problemas Brasileiros, SESC, São Paulo, n. 406, jul./ago., 2011. Disponível em: <https://www.sescsp.org.br/online/artigo/6041_liberdade+de+expressao>. Acesso em: 17 fev. 2017.

Liberdade de expressão e discurso do ódio. São Paulo: Revista dos Tribunais, 2009.

; CARCARÁ, Thiago Anastácio. Discurso de ódio e democracia: participação das minorias na busca pela tolerância. Anais do XXIII Encontro Nacional do CONPEDI, Florianópolis, Santa Catarina, p. 373 - 398, mai., 2014.

MILL, John Stuart. Sobre a liberdade. Tradução de Alberto da Rocha Barros. Rio de Janeiro: Vozes, 1992. 
NASCIMENTO, Amauri Mascaro. Curso de direito do trabalho: história e teoria geral do direito do trabalho, relações individuais e coletivas do trabalho. 26. ed. São Paulo:

Saraiva: 2011.

NASCIMENTO, Márcio Alessandro Neman do. Homofobia e homofobia interiorizada: produções subjetivas de controle heteronormativo? Revista Athenea Digital, n. 17, p. 227 - 239, mar. 2010, p. 236. Disponível

em<http://atheneadigital.net/article/download/n17-nascimento/652-pdf-pt>. Acesso em: 17 fev. 2017.

OMMATI, José Emílio Medauar. Liberdade de expressão e discurso de ódio na Constituição de 1988. 3. ed. Rio de Janeiro: Lumen Juris, 2016.

POTIGUAR, Alex Lobato. Discurso do ódio no Estado Democrático de Direito: o uso da liberdade de expressão como forma de violência. 2015. $196 \mathrm{f}$. Tese (Doutorado em Direito)—Universidade de Brasília, Brasília, 2015.

RIOS, Roger Raupp. Para um direito democrático da sexualidade. Horiz. antropol. [online]. 2006, vol. 12, n. 26, p. 71-100. Disponível em:

$<$ http://www.scielo.br/scielo.php?pid=S0104-

$71832006000200004 \&$ script=sci_arttext\&tlng=es >. Acesso em 01 ago. 2016.

ROCHA, Francielle Lopes; CARDIN, Valéria Silva Galdino. Do discurso do ódio contra as minorias sexuais como um instrumento de exclusão social. In: SIQUEIRA, Dirceu Pereira; AMARAL, Sérgio Tibiriça (org.). Op. cit., p. 193.

SARMENTO, Daniel. Livres e Iguais: Estudos de Direito Constitucional. Rio de Janeiro: Lumen Juris, 2006.

SILVA, Alexandre Assunção e. Liberdade de expressão e crimes de opinião. São Paulo: Atlas, 2012.

SILVA, José Afonso da. Direito Ambiental Constitucional. 4. ed. São Paulo: Malheiros, 2003.

Curso de Direito Constitucional Positivo. 15. ed. São Paulo: Malheiros, 1998.

SILVA, Rosane Leal da et al . Discursos de ódio em redes sociais: jurisprudência brasileira. Rev. direito GV, São Paulo, v. 7, n. 2, Dec. 2011. p.445-468. Disponível em: <http://www.scielo.br/scielo.php?script=sci_arttext\&pid=S1808-

$4322011000200004 \& \operatorname{lng}=\mathrm{en} \& \mathrm{nrm}=\mathrm{is}$ o>. Acesso em: 20 set. 2016.

Revista de Direito, Governança e Novas Tecnologias | e-ISSN: 2526-0049 | Brasília | v. 3 | n. 1 | p. 1 - 22 | Jan/Jun. 2017. 
SILVEIRA, Renata Machado da. Liberdade de expressão e discurso do ódio.

Dissertação (Mestrado em Direito) - Pontifícia Universidade Católica de Minas Gerais, Belo Horizonte, 2007.

VANEIGEM, Raoul. Nada é sagrado, tudo pode ser dito: Reflexões sobre a liberdade de expressão. Trad. Marcos Marcionilo. São Paulo: Parábola Breve, 2004. 